\title{
Bone Mineral Density In Different Stages Of Non Cholestatic Liver Cirrhoses
}

\author{
*Azza Emam. , ** Omer Hossian. And **Sherif Abou Gamrah . \\ Department of Internal Medicine. **Department of Radio diagnosis, \\ Ain Shams University.
}

\begin{abstract}
Hepatic osteodystrophy refers to metabolic Bone abnormalities observed in chronic liver disease. It is an important complication of chronic liver disease which includes osteoporosis and the much rare osteomalacia. It is varying from $13 \%$ to $70 \%$, depending on the population studied and the diagnostic criteria used to define bone disease.

The advances in bone densitometry and the development of newer techniques, such as dual energy x-ray absorptiometry (DEXA), make it possible to rapidly and precisely quantify the amount of bone in the relevant fracture sites. DEXA is noninvasive, rapid, accurate, and safe. So it is the gold standard with which all other technologies are compared.

So in this study, BMD was measured using DEXA technique at 2 sites; antro-posterior lumbar spines and femoral neck in 30 cirrhotic patients and 10 healthy volunteers as a control group.

In addition routine laboratory investigations; $\mathrm{CBC}, \mathrm{ESR}$, Liver function tests, renal function tests, serum $\mathrm{Na}, \mathrm{K}, \mathrm{Ca}$ and Phosphorus, urinary $24 \mathrm{~h} \mathrm{Ca}$ and viral markers; HBVs Ag and $\mathrm{HCV} \mathrm{Ab}$ was done and abdominal U/S.

We concluded that liver cirrhosis is a direct and independent risk factor for bone loss which is mainly in the form of osteoporosis rather than osteomalacia and the degree of bone loss is related to severity of the liver disease as it worsens as the liver function does. The trabecular bone is more clearly affected than cortical bone.

So BMD should be measured in cirrhotic patients and management should be started in osteopenic and osteoporotic patients and follow up should be done.
\end{abstract}

\section{Introduction}

An important complication of chronic liver disease is osteodystrophy which includes osteoporosis and the much rarer osteomalacia (collier et al., 2002). Hepatic osteodystrophy occurs in up to $50 \%$ of patients with chronic liver disease and is mainly due to an imbalance between bone formation and bone resorption that results in osteoporosis (crosbie et al., 1996).

Osteoporosis is defined as a progressive systemic skeletal disease characterized by low bone mass and micro architectural deterioration of bone tissue with a consequent increase in bone fragility and susceptibility to fracture (newton et al., 2001). In general, there are secondary factors such as malabsorption and nutritional deficiencies that may cause bone changes in chronic liver disease (mehmet et al., 2002).
The role of hepatocellular dysfunction in hepatic osteodystrophy is not clear. The risk of fracture increases progressively with decreasing bone mineral density (bmd), it increases two to three fold for each standard deviation (sd) decrease in bmd (marshal et al., 1996).

In recent years, with progress in the therapy of liver cirrhosis and its complications, there has been an increase in patient survival, as well as in the incidence of fractures and other manifestations of metabolic bone disease associated with chronic liver disease (duarte et al., 2001). For this reason, the management of hepatic osteodystrophy has become more important.

The advances in bone densitometry and the development of newer techniques, such as dual energy $\mathrm{x}$-ray absorptiometry 
(dexa), make it possible to rapidly and precisely quantify the amount of bone in the relevant fracture sites (brunader and shelton 2002). Dexa is noninvasive, rapid, accurate, and safe. So it is the gold standard with which all other technologies are compared (kanis and gluer, 2000).

So we aimed in this study to evaluate the frequency and severity of hepatic osteodystrophy in patients with liver cirrhosis and determine the role of the hepatocellular failure in bone loss.

\section{Patients and Methods}

This study had been carried out on thirty patients ( 9 females and 21 males) suffering from liver cirrhosis.

The patients were selected from the patients attending the gastroenterology and hepatology outpatients clinic or the patients admitted to the gastroenterology and hepatology unit, department of internal medicine, ain shams university hospital. Patients in our study were classified according to child-pugh classification of cirrhosis as follows:

Group i : included 10 patients "child a" Group ii : included 8 patients "child b". Groupiii: included 12 patients "child c".

Ten healthy volunteers ( 3 females and 7 males) were chosen as normal controls.

\section{Patients with any of the following were excluded:}

1- Female patients were on hormonal contraception or in postmenopausal periods.

2- Smoking or alcohol consuming patients

3- Patients who experienced periods of bed rest, immobilization, or using assistive devices for any activities of daily living.

4- Patients who had any secondary cause associated with osteoporosis or affects bmd other than liver cirrhosis.

5- Patients who were receiving any medical treatment that affects bmd.
All patients and controls were subjected to the following:

1- full history taking and thorough clinical examination to ensure that all patients included in the study fulfill the proper criteria for selection.

2- laboratory investigations including:

A- Complete blood picture by colter counter.

B- Erythrocyte sedimentation rate by westergren method.

C- Renal function tests (bun and serum creatinine). *

D- Liver function tests (total serum proteins, serum albumin, prothrombin time, alkaline phosphatase and liver enzymes; ast and alt). *

E- Randam blood sugar.*

F- Serum calcium, phosphorus, sodium, and potassium.*

G- Urinary 24 hour calcium levels. *by synchrone, cx 5 delta.

3- abdominal ultrasonography for:

a. Liver size and echopattern.

b. Spleen size and signs of portal hypertension.

c. Presence of ascites.

d. Excluding other accidentally discovered findings.

4- measurement of bone mineral density using lunar dpx-iq dexa densitometer (u.s.a) at the lumbar spines and femur neck.

\section{Statistical methods:}

The data were collected then analyzed statistically using spss statistical package version (11).

The following tests were done:

- Mean (x).

- Standard deviation ( $\pm \mathrm{sd})$.

- Anova test (f) for analysis of variants.

- Post hock test to detect the least significance difference (lsd).

- Student $\mathrm{t}$ - test $(\mathrm{t})$ in independent samples.

- $\mathrm{X} 2=$ chi- square tests. 
- Correlation co-efficient test (r-test) to find a linear relation between different values.

Level of significance $=p$ value .

- $\quad$ P> 0.05 i.e. not significant (ns)

- $\quad P<0.05$ i.e. significant (s).

- $\mathrm{P}<0.01$ i.e. high significant (hs).

\section{Results}

The patients and the controls were matched as regarded age and sex (with no significant statistical difference $\mathrm{p}>0.05$ ).the mean age of the patients was $41.1+_{-} 8.04$ years, while it was $38.2+\ldots 4.9$ years in the controls.

Evaluation of bmd according to who classification showed, highly significant difference between all patients and controls ( $<<0.01)$; cirrhotic patients showed $40 \%$ osteoporosis, 50\% osteopenia, and 10\% with normal bmd, while $30 \%$ of controls had osteopenia.

An increase in the percentage of osteoporosis was observed with the increase in the severity of cirrhosis according to child-pugh classification ( osteoporosis was observed in 30\% of group i patients, 37.5\% of group ii patients, and 50\% of group iii patients ). Osteopenia was also observed in $50 \%$ of group i patients, $62.5 \%$ of group ii, and $41.7 \%$ of group iii patients.

The data of the patients and controls were summarized and tabulated as follow:

Table (1): Showed no significant difference between all patients and controls as regards s.ca, s.po4 or u.24 h ca (p>0.05) while there was highly significant elevation of s.alp $(\mathrm{p}<0.01)$ in the patients.

Table (2) Showed no significant difference among 3 groups of patients and control group as regards s.ca, s.po4 or u. $24 \mathrm{~h} \mathrm{ca}$ (p>0.05). While there was highly significant difference among 3 groups of patients and controls as regards s.alp $(\mathrm{p}<0.01)$. By doing post-hock test to detect the least significant difference (lsd), there was highly significant increase in group ii and iii when compared to control $(\mathrm{p}<0.01)$, while there was no significant difference between group ii and group iii or between control group and group $\mathrm{i}$ $(\mathrm{p}>0.05)$.

Table(3): Showed highly significant difference between all patients and controls as regards a-p lumbar spines $(\mathrm{p}<0.01)$, while no significant difference between each other as regards femoral neck ( $>0.05)$.

Table (4): Showed no significant statistical difference between males and females patients as regards bmd measu-rement by dexa in t-score at a-p lumbar spines (a-p 1.s.) and femoral neck (f.n.).

Table(5): Showed highly significant difference among 3 groups of patients and control group as regards a-p lumbar spines $(\mathrm{p}<0.01)$. By doingpost-hock test to detect lsd, there was highly significant decrease in bone dencity in group ii and group iii when compared with control group $(\mathrm{p}<0.01)$, while there was no significant difference between group ii and group iii or between group $i$ and control group $(p>0.05)$.

Table(6): Showed no significant correlation between bmd measurements at both lumber spines and femoral neck with liver function tests $(\mathrm{p}>0.05)$.

Table(7): Showed no significant correlation between bmd measurements at both lumber spines and femoral neck with markers of bone loss ( $p>0.05$ ).

Figure(1): Showed bone density scan. Lumbar spine bone density of a 39 years old child $\mathrm{c}$ male patient showing osteopenia (t-score -1.9).

Figure(2): Showed bone density scan. Femoral neck bone density of a 39 years old child a female patient showing osteopenia ( $\mathrm{t}$-score -1.6).

Figure(3): Showed bone density scan. Lumbar spine bone density of a 38 years old child $b$ male patient showing osteoporosis (t-score -3.1).

Figure(4): Showed bone density scan. Femoral neck bone density of a 25 years old child a male patient showing osteoporosis (t-score -2.6). 
Table (1): Comparative study between patients and controls as regards markers of bone loss.

\begin{tabular}{|l|l|l|l|l|l|l|l|}
\hline \multirow{2}{*}{ Parameter } & \multicolumn{3}{|l|}{ Patients } & \multicolumn{2}{l|}{ Controls } & \multirow{2}{*}{ P } & \multirow{2}{*}{ Sig. } \\
\cline { 2 - 7 } & $\mathrm{X}$ & SD & $\mathrm{X}$ & SD & & & \\
\hline s.ALP & 133.93 & 61.89 & 68.1 & 17.19 & 3.3 & $<0.01$ & H.S. \\
\hline s.Ca & 9.3 & 0.36 & 9.5 & 0.43 & -1.5 & $>0.05$ & N.S. \\
\hline s.PO & 3.05 & 0.56 & 3.3 & 0.25 & -1.5 & $>0.05$ & N.S. \\
\hline U.24h Ca & 160.5 & 44.72 & 167.56 & 45.5 & -0.43 & $>0.05$ & N.S. \\
\hline
\end{tabular}

Table (2): Comparison among the 3 groups of patients and control group as regards markers of bone loss.

\begin{tabular}{|c|c|c|c|c|c|c|c|c|c|c|c|}
\hline \multirow{2}{*}{ Parameter } & \multicolumn{2}{|l|}{$\bar{I}$} & \multicolumn{2}{|l|}{ II } & \multicolumn{2}{|l|}{ III } & \multicolumn{2}{|l|}{ Control } & \multirow{2}{*}{$F$} & \multirow{2}{*}{$\mathrm{P}$} & \multirow{2}{*}{ Sig. } \\
\hline & $\mathrm{X}$ & SD & $\mathrm{X}$ & SD & $\mathrm{X}$ & SD & $\mathrm{X}$ & SD & & & \\
\hline s.ALP & 92.8 & 31.54 & 135 & 58.37 & 167.5 & 65.95 & 68.1 & 17.19 & 9.07 & $<0.01$ & HS \\
\hline s.Ca & 9.28 & 0.29 & 9.09 & 0.53 & 9.46 & 0.2 & 9.51 & 0.43 & 2.47 & $>0.05$ & N.S. \\
\hline s.PO & 3.04 & 0.39 & 3.28 & 0.52 & 2.94 & 0.7 & 3.33 & 0.25 & 1.3 & $>0.05$ & N.S. \\
\hline U.24h Ca & 176.86 & 43.93 & 144.4 & 39.95 & 157.61 & 47.29 & 167.56 & 45.5 & 0.87 & $>0.05$ & N.S. \\
\hline
\end{tabular}

Table (3): Comparative data between patients and controls as regards BMD measurement by DEXA in T-score at A-P lumbar spines (A-P L.S.) and femoral neck (F.N.).

\begin{tabular}{|l|l|l|l|l|l|l|l|}
\hline \multirow{2}{*}{ Parameters } & \multicolumn{2}{|l|}{ Patients } & \multicolumn{2}{|l|}{ Controls } & \multirow{2}{*}{ T } & \multirow{2}{*}{ P } & \multirow{2}{*}{ Sig. } \\
\cline { 2 - 5 } & $\mathrm{X}$ & $\mathrm{SD}$ & $\mathrm{X}$ & $\mathrm{SD}$ & & & \\
\hline A-P L.S. & -1.82 & 1.05 & -0.85 & 0.36 & -2.85 & $<0.01$ & H.S. \\
\hline F.N. & -0.69 & 1.08 & -0.42 & 0.48 & -0.75 & $>0.05$ & N.S. \\
\hline
\end{tabular}

Table (4): Comparative data between males and females patients as regards BMD measurement by DEXA in T-score at A-P lumbar spines (A-P L.S.) and femoral neck (F.N.).

\begin{tabular}{|l|l|l|l|l|l|l|l|}
\hline \multirow{2}{*}{ Parameters } & \multicolumn{2}{|l|}{ Males } & \multicolumn{2}{l|}{ Females } & \multirow{2}{*}{ T } & \multirow{2}{*}{ P } & \multirow{2}{*}{ Sig. } \\
\cline { 2 - 5 } & $\mathrm{X}$ & SD & $\mathrm{X}$ & SD & & & \\
\hline A-P L.S. & -1.89 & 0.96 & -1.82 & 1.02 & 0.175 & $>0.05$ & N.S. \\
\hline F.N. & -0.09 & 0.909 & -0.44 & 0.06 & 1.2 & $>0.05$ & N.S. \\
\hline
\end{tabular}

Table (5): Comparative data as regards BMD measurements by DEXA in T-score among 3 groups of patients and control group at A-P lumbar spines and femoral neck.

\begin{tabular}{|l|l|l|l|l|l|l|l|l|l|l|l|l|}
\hline \multirow{2}{*}{ Parameter } & I & \multicolumn{3}{|l|}{ II } & III & \multicolumn{2}{|l|}{ Control } & F & P & Sig. \\
\cline { 2 - 11 } & X & SD & X & SD & X & SD & X & SD & & $<0.0$ & HS \\
\hline A-P L.S. & -1.32 & 1.1 & - & 2.23 & 0.89 & -1.9 & 1.02 & -0.85 & 0.36 & 4.6 & $\begin{array}{l}1 \\
1\end{array}$ \\
\hline F.N. & -0.65 & $\begin{array}{l}1.2 \\
1\end{array}$ & -0.5 & 0.59 & - & 1.26 & -0.42 & 0.48 & $\begin{array}{l}0.3 \\
8\end{array}$ & $\begin{array}{l}>0.0 \\
5\end{array}$ & N.S. \\
\hline
\end{tabular}

Table (6): Correlation between BMD measurements at both lumber spines and femoral neck with liver function tests.

\begin{tabular}{|l|l|l|l|l|}
\hline \multirow{2}{*}{ Parameters } & A-P L.S. & \multicolumn{3}{l|}{ F.N. } \\
\cline { 2 - 5 } & R & P & r & P \\
\hline Alb & -0.27 & 0.15 & 0.13 & 0.5 \\
\hline PT & -0.08 & 0.66 & -0.21 & 0.27 \\
\hline T.Bil & 0.09 & 0.64 & -0.05 & 0.8 \\
\hline Indirect Bil & 0.11 & 0.57 & -0.07 & 0.73 \\
\hline
\end{tabular}


Table (7): Correlation between BMD measurements at both lumber spines and femoral neck with markers of bone loss.

\begin{tabular}{|l|l|l|l|l|}
\hline \multirow{2}{*}{ Parameters } & \multicolumn{2}{l|}{ A-P L.S. } & \multicolumn{2}{l|}{ F.N. } \\
\cline { 2 - 5 } & $\mathrm{R}$ & $\mathrm{P}$ & $\mathrm{r}$ & $\mathrm{P}$ \\
\hline $\mathrm{ALP}$ & -0.27 & 0.15 & 0.05 & 0.81 \\
\hline $\mathrm{Ca}$ & -0.02 & 0.92 & 0.09 & 0.64 \\
\hline $\mathrm{PO}_{4}$ & -0.05 & 0.78 & 0.17 & 0.37 \\
\hline U.24h Ca & 0.07 & 0.73 & 0.04 & 0.82 \\
\hline
\end{tabular}
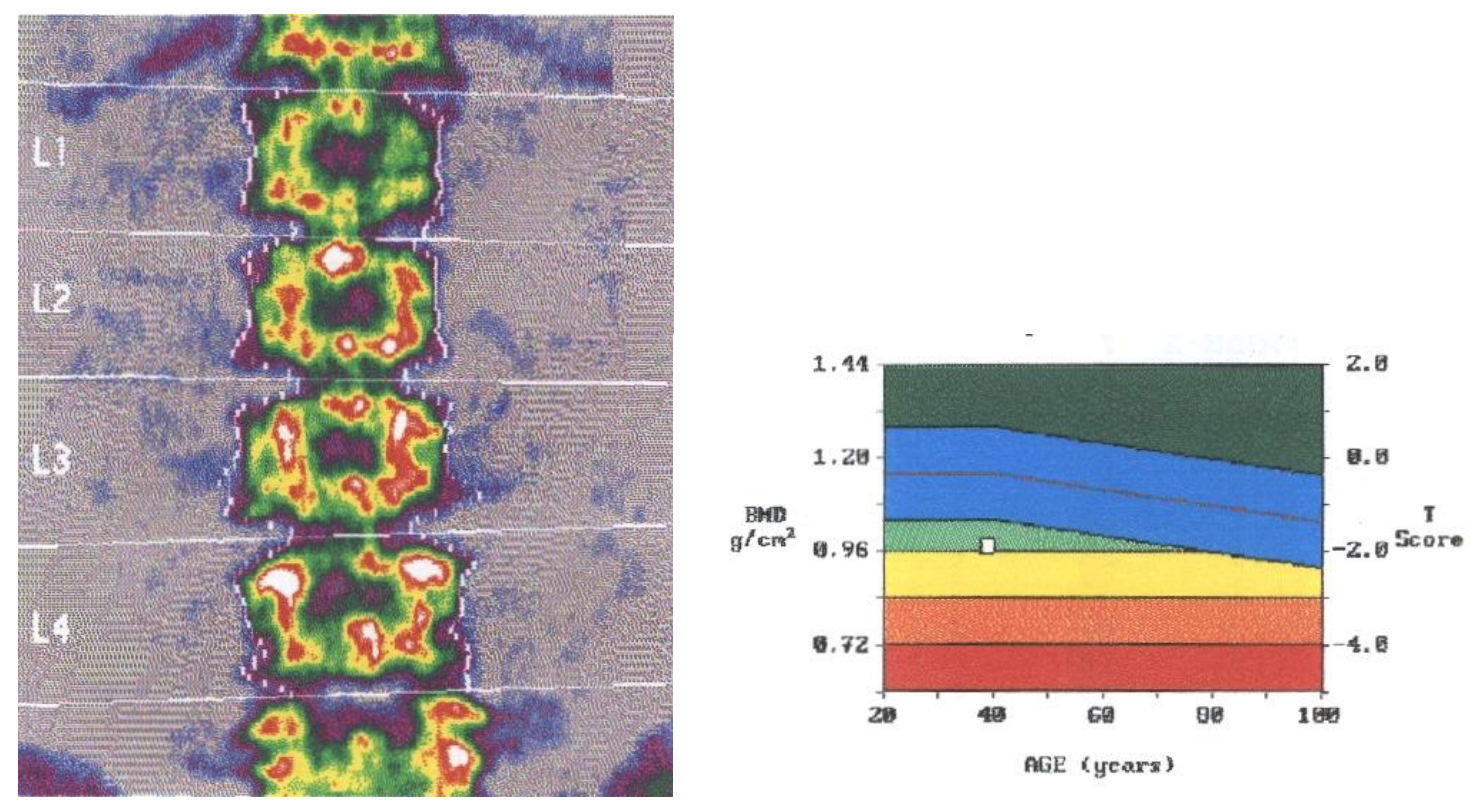

Figure (1): Bone density scan. Lumbar spine bone density of a 39 years old Child C male patient showing osteopenia (T-score -1.9). 

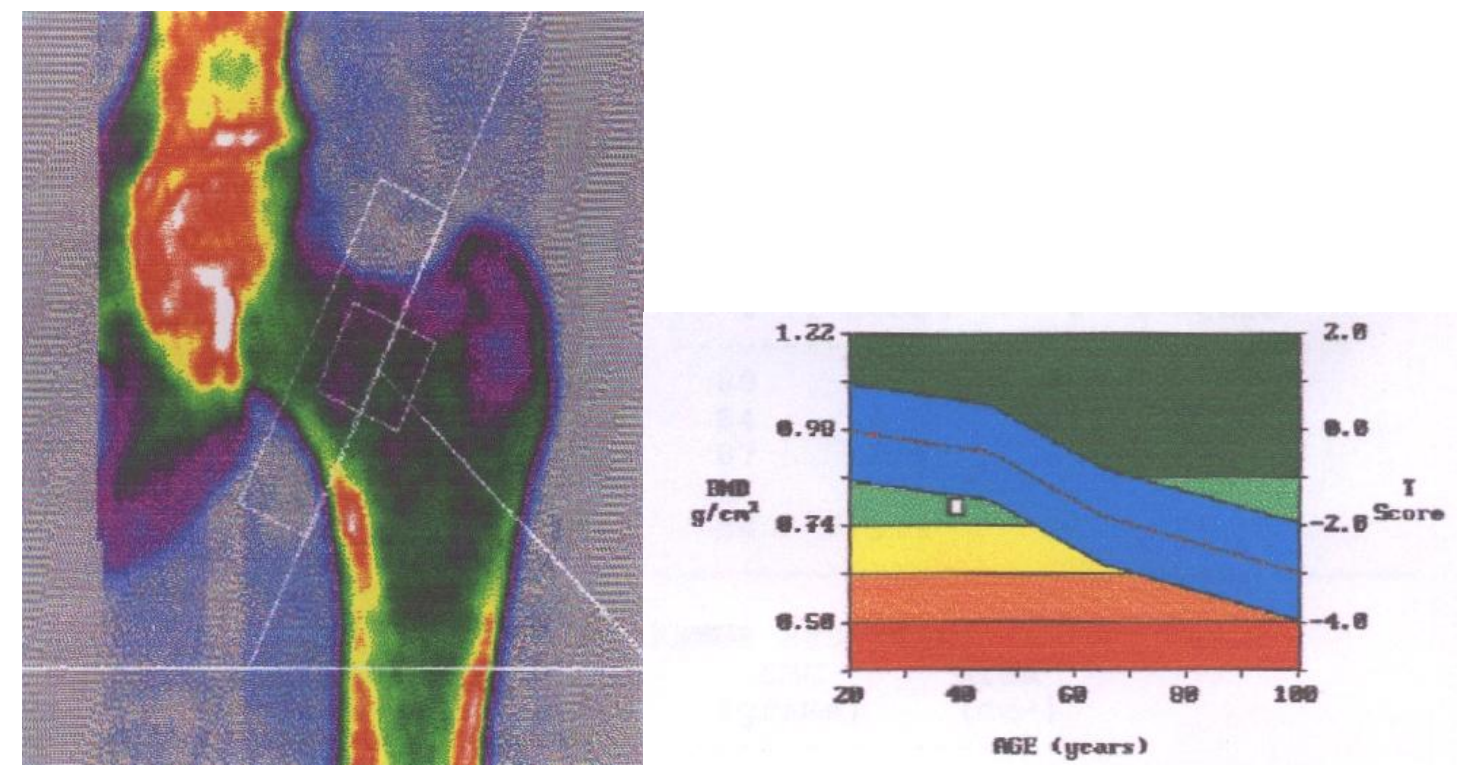

Figure (2): Bone density scan. Femoral neck bone density of a 39 years old Child A female patient showing osteopenia ( $\mathrm{T}$-score -1.6).
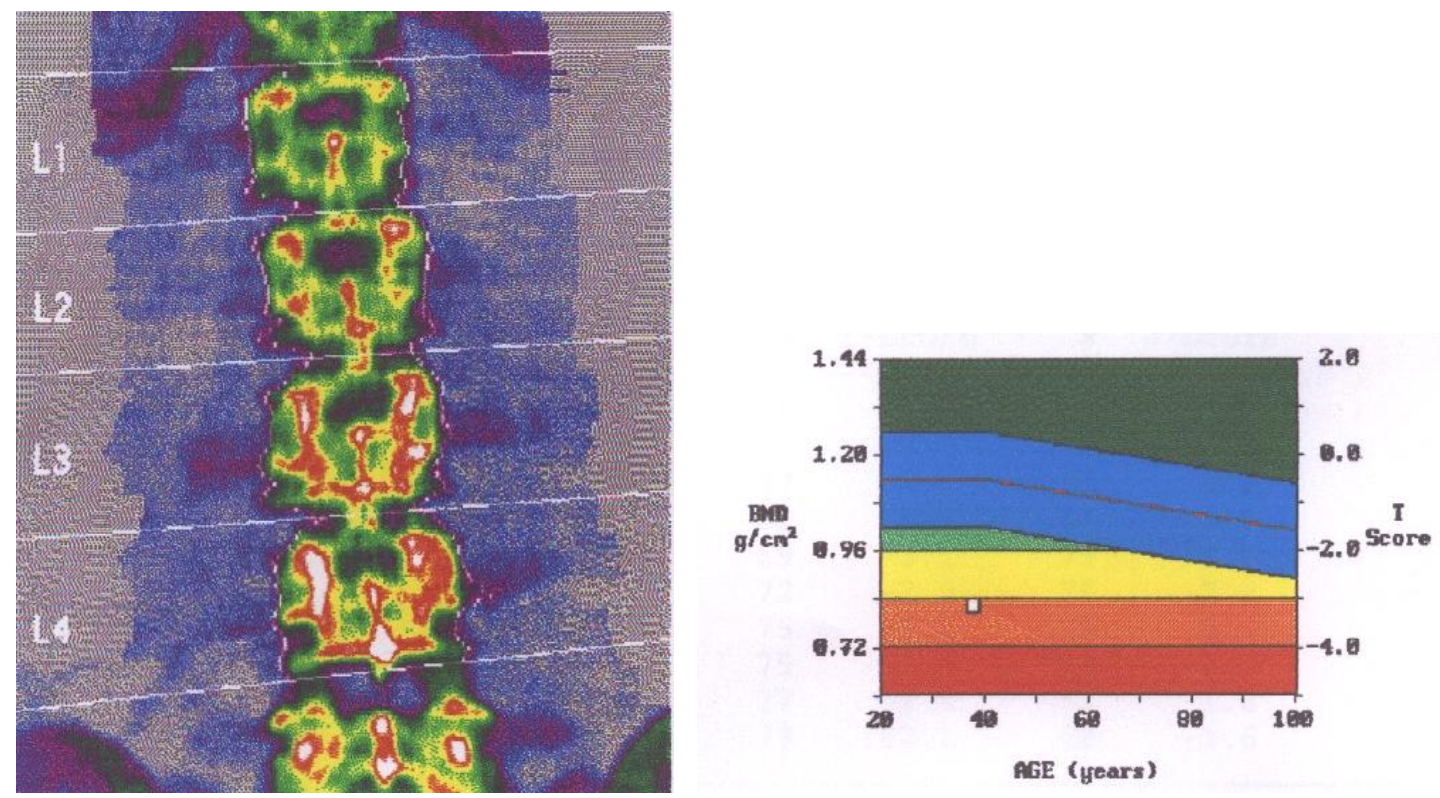

Figure (3): Bone density scan. Lumbar spine bone density of a 38 years old Child B male patient showing osteoporosis ( $\mathrm{T}$-score $\mathbf{- 3 . 1}$ ). 

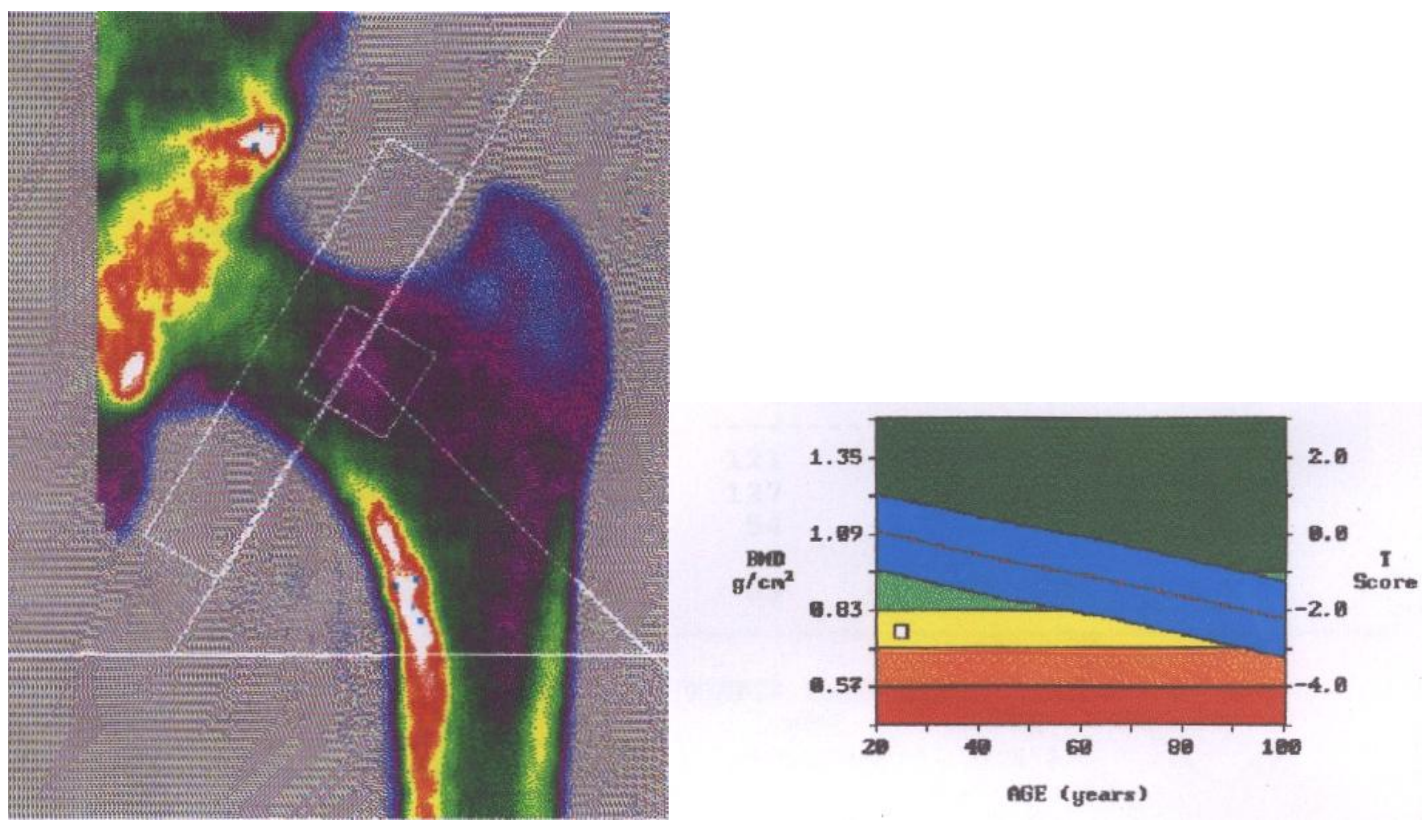

\section{Figure (4): Bone density scan. Femoral neck bone density of a 25 years old Child A male patient showing osteoporosis ( $\mathrm{T}$-score -2.6).}

\section{Discussion}

Hepatic osteodystrophy is an important complication of chronic liver disease. Osteoporosis accounts for the majority of cases whereas osteomalacia is rare in the absence of advanced liver disease and severe malabsorption (Rouillard and Lane, 2001).

Osteodystrophy occurs in up to $50 \%$ of patients with chronic liver disease (Crosbie et al., 1996). It is varying from $13 \%$ to $70 \%$, depending on the population studied and the diagnostic criteria used to define bone disease (Duarte et al., 2001).

In evaluation of both patients and controls according to WHO classification of osteoporosis, we found that $90 \%$ of cirrhotic patients had hepatic osteodystrophy (osteoporosis in 50\% and osteopenia in $40 \%$ ) while $30 \%$ of normal control showed decrease BMD in the form of osteopenia which may be due to either lack of calcium, vitamin D supplementation, and/or lack of physical activity among our controls. As inadequate intake of dietary calcium , vitamin $\mathrm{D}$, and physical activity may contribute to achievement of a lower than expected peak bone mass as well as excessive bone loss and higher fracture risk later on (Lane, 1998 and Becker, 2003).

The role of vitamin D in hepatic osteodystrophy is controversial , GallegoRojo et al. (1998) found reduction in serum 25(OH)D in Child B and Child C cirrhotic patients with viral liver disease. Rouillard and Lane, (2001) stated that there was an increase in osteoclastic activity with higher turnover osteoporosis in cholestatic liver disease only due to vitamin D deficiency . While Duarte et al. (2001) did not find 25(OH)D deficiency.

In studying the serum calcium and phosphorus levels as well as the 24 hour urinary excretion of calcium (Table1), no significant statistical difference were found when compared to normal control. Also among patient groups (Child A, Child B, Child C) (Table2), no significant statistical difference was found. In addition, there was no correlation between these parameters and BMD measurements at lumbar spines or at femoral neck among cirrhotic patients (Table7). 
Mehmet et al. (2001) and Duarte et al. (2001) also found no significant correlation between serum calcium, phosphorus, PTH, and $25(\mathrm{OH}) \mathrm{D}$ and severity of bone loss. This might indicate that osteoporosis rather than osteomalacia is involved in the pathogenesis of the hepatic osteodystrophy in chronic liver disease.

As regards serum Total alkaline phosphatase (Table1), it was elevated in patients more than control with highly significant statistical difference. Also among groups of patients and control (Table2), it showed highly significant statistical differences between control and patients in Child B and Child C. This was in agreement with Gallego-Rojo et al. study (1998) who found elevation of serum b-AP in patients with advanced liver disease (Child B and Child C) which may reflect higher bone formation rates.

Using the current generation of DEXA systems, images can be obtained in about 2 minutes and there is a sufficiently high resolution to measure geometrical features as well as bone mineral density (BMD). Radiation doses are very low and precision errors are small (Young, 2003).

The high level of precision of this technique allows Its uses not only for diagnosis, but also for monitoring response to therapy (Kanis and Gluer, 2000). It is noninvasive, rapid, accurate, and safe. So it is the gold standard with which all other technologies are compared (Miller et al., 1999).

So in this study, DEXA was used to assess BMD in the patients and the control at two axial sites; the lumbar spines and the femoral neck.

In this study Osteoporosis was noticed in 30\% of Child A patients, $37.5 \%$ of ChildB, $50 \%$ of Child C patients.

Which was matched with the results of the previous researches. Gallego-Rojo et al. (1998) found that there was increase in the percentage of osteoporosis with the increase of the severity of cirrhosis. They reported $37.5 \%$ of Child A patients, $60 \%$ of Child B patients, $66 \%$ of Child $\mathrm{C}$ patients were osteoporotics. Also Corazza et al. (2000) demonstrated that the progression of the disease from Child $\mathrm{A}$ to Child $\mathrm{C}$ is accompanied by worsening of BMD measurement.

Also no significant difference was noticed between males and females $(\mathrm{P}>0.05)$ (Table 4). This can be explained by the fact that all females in this study was in the fertile age .

To evaluate which type of bone is more affected, studying of BMD by DEXA at lumbar spines (i.e.: trabecular bone) and femoral neck (i.e.: cortical bone) was done. Our results demonstrated that there was decrease in BMD at both sites in cirrhotic patients (mean T- score was -1.82 \pm 1.05 and $0.69 \pm 1.08$ for trabecular and cortical bone respectively) (Table3.

The trabecular bone (lumbar spines) was more affected than cortical with highly significant difference between cirrhotic patients and controls as regards trabecular bone (lumbar spines) but no significant difference between cirrhotic patients and controls as regards cortical bone (femoral neck). This is probably because the rate of turnover in the cortical bone is much lower than in trabecular bone. This was in agreement with Duarte et al. (2001) who found that mean $\mathrm{T}$ - score was more negative in areas where trabecular bone predominates, such as lumbar spine.

Also Gallego-Rojo et al. (1998) reported that BMD at both lumbar spines and femoral neck were significantly lower in cirrhotic patients than reference population. Bone loss at lumbar spines (trabecular bone) was more sever than in femoral neck (cortical bone). We attributed the significant difference between their patients and controls as regards femoral neck BMD(cortical bone), due to higher age of their patients (mean age 58 years, range $38-74$ years) especially that senility affects the cortical and the trabecular bone in the same degree.

Also our results demonstrated highly significant increase in BMD loss at lumbar spines in Child B and Child C when compared with controls with no significant difference between Child B and Child C or between Child A and controls (Table 5)

As regards BMD measurement at femoral neck, there was no significant statistical difference among all groups of patients 
when compared with each others and with controls.

Gallego-Rojo et al. (1998) reported that BMD at lumbar spines was significantly lower in Child B and Child C patients than in Child $\mathrm{A}$ patients and no significant difference between Child B and Child C patients. Also Corazza et al. (2000) found that lumbar mean BMD values worsened progressively from Child A to Child C patients, So they concluded that the prevalence of bone loss increased progressively from Child A to Child C patients.

We conclude that liver cirrhosis is a direct and independent risk factor for bone loss which is mainly in the form of osteoporosis rather than osteomalacia and the degree of bone loss is related to severity of the liver disease as it worsens as the liver function does. The trabecular bone is more clearly affected than cortical bone.

So we recommended that BMD should be evaluated in cirrhotic patients. Management and follow up should be done in osteopenic and osteoporotic patients.

\section{References}

1. Becker C. Clinical evaluation for osteoporosis. Clinics in Geriatric Medicine 2003; 19: 807.

2. Brunader $\mathbf{R}$ and Shelton DK. Radiologic Bone Assessment in the Evaluation of Osteoporosis. American Family Physician 2002; 65(7):403.

3. Collier JD, Ninkovic M, and Compston JE. Guidelines on the management of osteoporosis associated with chronic liver disease. Gut 2002; 50 (1):11.

4. Crosbie O M, Freaney R, and Mc Kenna MJ. Assessment of fracture risk in patients with chronic liver disease .Ir J Med Sd 1996; 165(2): 5 .

5. Kanis JA and Gluer CC. An update on the diagnosis and assessment of osteoporosis with densitometry. Committee of Scientific Advisors, International osteoporosis Foundation. Osteoporosis Int 2000; 11:192.

6. Lane NE. Risk factors for osteoporosis. In: Rheumatology ( $2^{\text {nd }}$ edition). Kipple $\mathbf{J} \mathrm{H}$ and Dieppe $\mathrm{P}$ (editors). Mosby Boston. 1998; P.8:38.1.

7. Marshal D,Jonhell $\mathbf{O}$, and Wedel $\mathbf{H}$. Meta-analysis of how well measures of bone mineral density predict occurrence of osteoporotic fractures. Br.J.Med 1996; 312:1254.

8. Mehmet A K, Nilgun E, and Cemil T. Osteodystrophy in Posthepatitic Cirrhosis. Yonsie Medical Journal 2002;42(5): 547.

9. Miller PD, Zapalowaski C, Kulak C, and Bilezikian JP. Bone Densitometry: The Best Way to Detect osteoporosis and to Monitor Therapy. Journal of Clinical Endocrinology and Metabolism 1999; 84(6): 1867.

10. Newton J, Francis R, Prince $M$, and James O. Osteoporosis in Primary biliary cirrhosis revisited. Gut 2001; 49:282. Rouillard S and Lane NE. Hepatic osteodystrophy. Hepatology 2001; 33(1):302.

11. Young JW. Metabolic and endocrine disorders affecting bone. In:Textbook of radiology and imaging( $7^{\text {th }}$ ed. $)$. Sutton D (editor). Churchill Livingstone London. 2003; P.1351. 


\title{
قياس كثافة العظام في مرضى التليف الكبدي بدون صفراء انسدادية
}

\author{
د.عزة امام ,** د.عمر حسبن و**د. شريف أبو جمرة

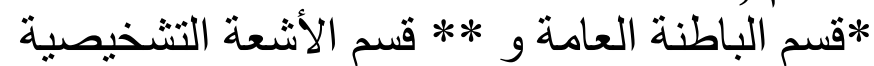

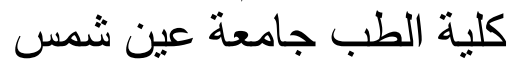

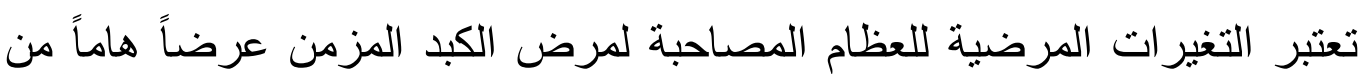

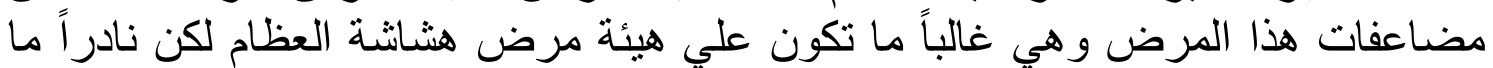

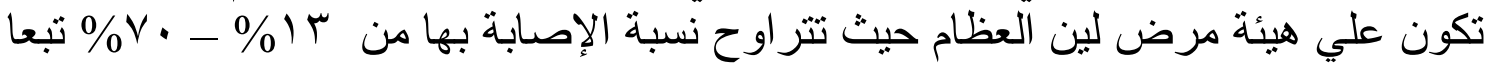

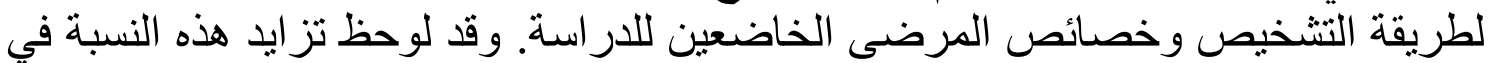

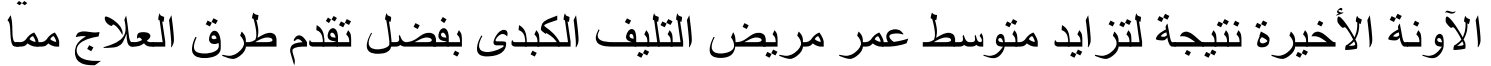

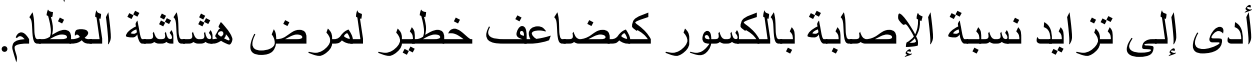

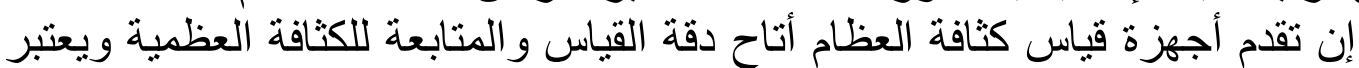

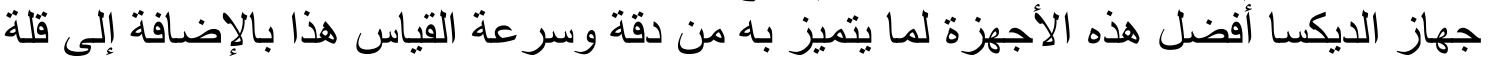

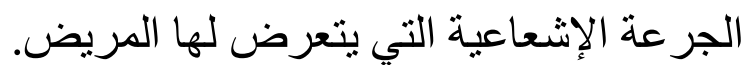
لذا أجريت هذه الدراسة حيث تم قئ قياس الكثافة العظمية باستخدام جهاز الديكسا في كل

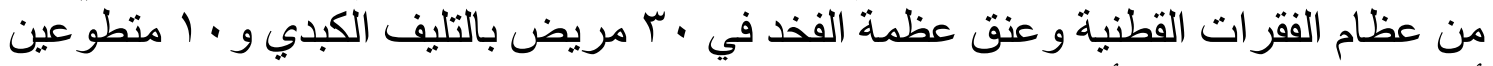

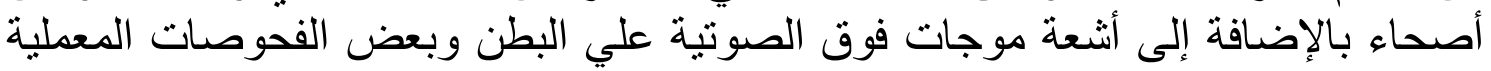

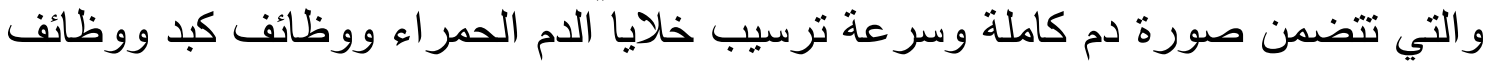

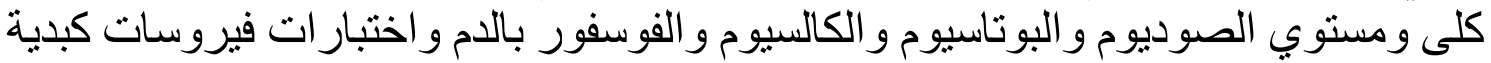
ومعدل الكالسيوم في بول يول يوم كامل.

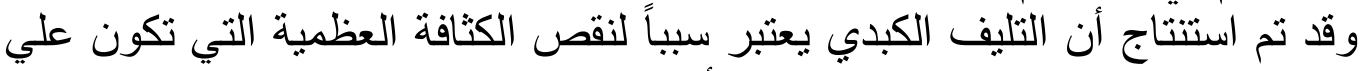

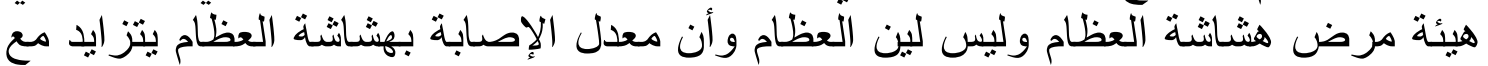

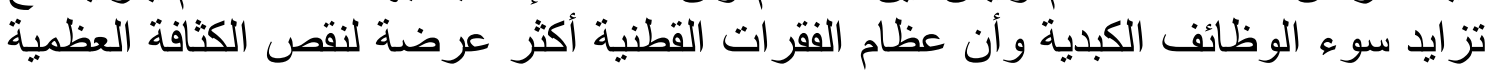
من عظمة عنق الفخد. لذا ننصح بقياس الكثافة العظمية لمرضي التليف الكبدي و المتابعة الطبية لها. 